\section{Spontaneous coronary artery dissection resulting in very late stent thrombosis}

A 58-year-old man with a history of coronary angioplasty done to right coronary artery 6 years back presented to the hospital with sudden-onset chest pain for $1 \mathrm{~h}$. His ECG on admission revealed ST elevation in leads II, III and augmented vector foot (aVF). The patient was thrombolysed with streptokinase, which resulted in resolution of chest pain and ECG changes. Three hours later there was reappearance of ST elevation in same leads with cardiogenic shock. It was decided to take the patient for rescue angioplasty. Angiogram revealed significant luminal stenosis of proximal right coronary artery along with in-stent thrombotic occlusion (see online supplementary video 1 ). The optical coherence tomography (OCT) study showed evidence of coronary dissection with intramural haematoma proximal to stent extending well into the stent along with in-stent restenosis and extensive thrombus load. However, there was no evidence of late stent malapposition or neointimal rupture (figure 1, see online supplementary video 2). Postimplant OCT images revealed good stent apposition (figure 2, see online supplementary video 3). Recent studies using intravascular ultrasound and OCT suggest that delayed neointimal coverage over stent struts, late stent malapposition, neointimal atherosclerotic change and delayed arterial healing are associated with very late stent thrombosis (VLST). ${ }^{1}$ Some studies report up to $20 \%$ prevalence of neointimal rupture in patients presenting with VLST. $^{2}$

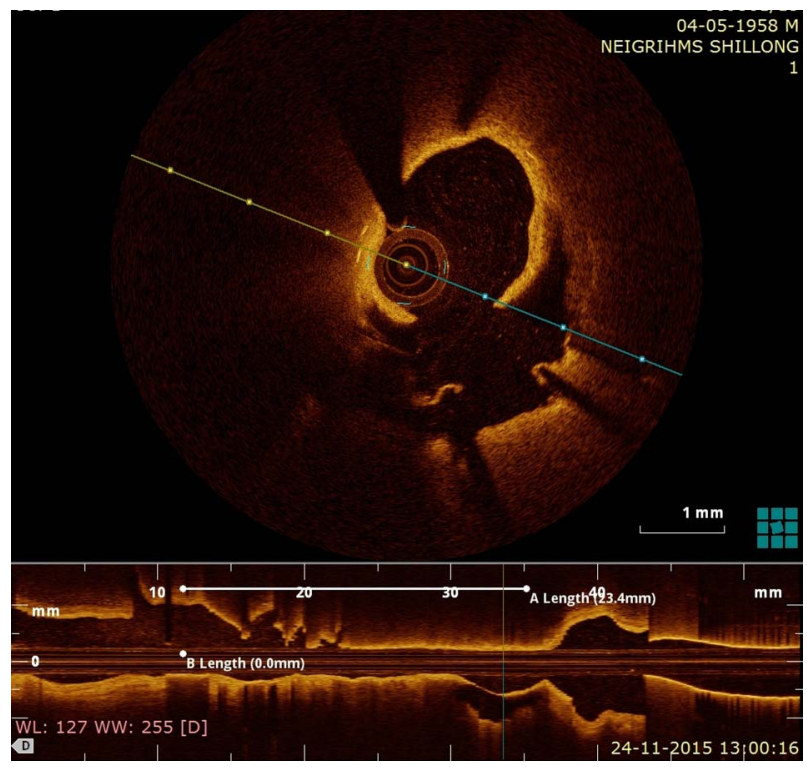

Figure 1 Pre-percutaneous coronary intervention optical coherence tomography image.

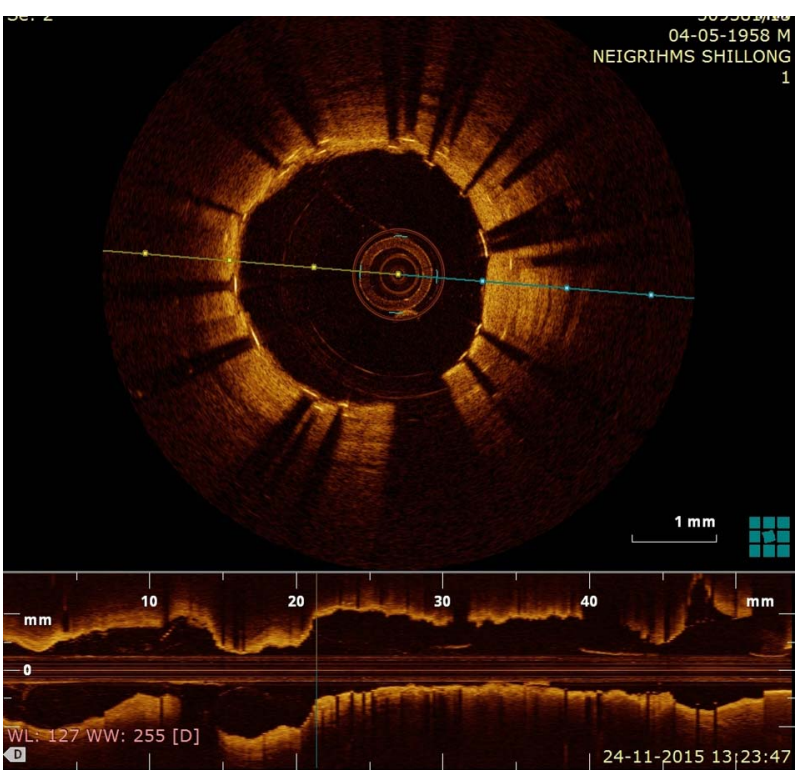

Figure 2 Post-percutaneous coronary intervention optical coherence tomography image.

Postimplant residual edge dissections are a known factor for stent thrombosis but to the best of our knowledge spontaneous dissection of coronary artery leading to VLST has not been reported.

Amit Malviya, Dhanjit Nath, Animesh Mishra

Department of Cardiology, Northeastern Indira Gandhi Regional Institute of Health and Medical Sciences (NEIGRIHMS), Shillong, Meghalaya, India

Correspondence to Dr Animesh Mishra, Department of Cardiology, North Eastern Indira Gandhi Regional Institute of Health and Medical Sciences, Shillong 18, Meghalaya, India; animesh.shillong@gmail.com

Contributors All authors contributed in drafting, revision and final approval the manuscript and are accountable for all aspects of the work in ensuring that questions related to the accuracy or integrity of any part of the work are appropriately investigated and resolved.

Competing interests None declared.

Patient consent Obtained.

Provenance and peer review Not commissioned; externally peer reviewed.

- Additional material is available. To view please visit the journal online (http://dx. doi.org/10.1136/heartasia-2015-010720).

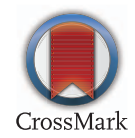

To cite Malviya A, Nath D, Mishra A. Heart Asia 2016;8:27. doi:10.1136/ heartasia-2015-010720

Heart Asia 2016;8:27. doi:10.1136/heartasia-2015-010720

\section{REFERENCES}

1 Siddiqi OK, Faxon DP. Very late stent thrombosis: current concepts. Curr Opin Cardiol 2012;27:634-41.

2 Ko YG, Kim DM, Cho JM, et al. Optical coherence tomography findings of very late stent thrombosis after drug-eluting stent implantation. Int I Cardiovasc Imaging 2012;28:715-23. 